\title{
openheart Do EXCEL and NOBLE translate into real world? A 5-year observational study of left main stem outcomes
}

\author{
George Joy (i) , ${ }^{1}$ Hany Eissa ${ }^{2}$
}

To cite: Joy G, Eissa H. Do EXCEL and NOBLE translate into real world? A 5-year observational study of left main stem outcomes. Open Heart 2020;7:e001347. doi:10.1136/ openhrt-2020-001347

Received 24 May 2020 Revised 16 August 2020 Accepted 5 0ctober 2020

\section{Check for updates}

(c) Author(s) (or their employer(s)) 2020. Re-use permitted under CC BY-NC. No commercial re-use. See rights and permissions. Published by BMJ.

${ }^{1}$ Cardiology, Barts Health NHS Trust, London, UK ${ }^{2}$ Cardiology Department, Queen Elizabeth Queen Mother Hospital, Margate, UK

Correspondence to Dr George Joy; g.joy@nhs.net

\section{ABSTRACT}

Aims We aimed to uncover the 5-year real world outcomes of patients with significant left mainstem (LMS) disease managed with percutaneous coronary intervention (PCI), coronary artery bypass graft (CABG) or medical management.

Methods We identified patients with LMS disease in 2012 and analysed baseline characteristics and outcomes in the following 5 years.

Results 119 patients were identified, $62 \%$ (74) received CABG and $12 \%$ (14) received $\mathrm{PCl}$ and $26 \%$ (31) were medically managed. In PCl versus $\mathrm{CABG}$, there was no significant difference in age and Synergy between $\mathrm{PCl}$ with Taxus and Cardiac Surgery score but there were significantly higher rates of pretreatment heart failure (ejection fraction $42 \% \pm 10$ vs $52 \% \pm 13 p=0.01$ ). Overall major adverse cardiovascular event (MACE) being a composite of stroke, myocardial infarction (MI), target vessel revascularisation and all-cause mortality were not statistically different but numerically higher in the $\mathrm{PCl}$ group ( $36 \%$ (5) vs $23 \%$ (17) $p=0.12$ ). Medically managed patients were significantly older than those that were revascularised ( $\mathrm{PCl}$ or $\mathrm{CABG} n=88 ; 75 \pm 11$ vs $69 \pm 9$ years $\mathrm{p}=0.01)$. They also had higher MACE $(74 \%(23)$ vs $25 \%$ (22) $p=0.000002)$ driven by Ml ( $19 \%$ (6) vs $2 \%$ (1) $p=0.01)$ and all-cause mortality $(52 \%$ (16) vs $19 \%$ (17) $p=0.01)$ compared with those with revascularisation.

Conclusions The bleak outcomes of medical management in LMS disease are reflective findings from studies performed from several decades ago. Our findings show that there is still a role for $\mathrm{PCl}$ in the management of LMS disease in selected patients.

\section{INTRODUCTION}

Left mainstem (LMS) disease represents higher risk to the patient due to the large territory of left ventricular myocardium under threat; it supplies $100 \%$ of the left ventricle in left dominant systems and $75 \%$ in right dominance. Stenosis of this vessel is therefore associated with a higher risk of heart failure and arrhythmia than non-LMS disease. The LMS comprises more elastic smooth muscle of the coronary vessels and therefore can lead to procedural unpredictability and restenosis. ${ }^{1}$

Significant LMS disease (angiographic stenosis $>50 \%$ ) has been historically reserved

\section{Key questions}

What is already known about this subject?

- EXCEL and NOBLE reported vastly differing outcomes in the management of left mainstem disease with EXCEL showing non-inferiority of percutaneous coronary intervention $(\mathrm{PCl})$ to coronary artery bypass graft (CABG), and NOBLE reporting superiority of $\mathrm{CABG}$ to $\mathrm{PCl}$. Medical management of left mainstem disease has historically carried dismal outcomes with a quoted mortality of approximately $50 \%$ at 5 years; however, this was based on studies performed over 20 years ago.

What does this study add?

- This study provides real-world outcomes of treatment of left mainstem disease where we included patients that would have been excluded from large trials due to a lack of clinical equipoise between the two treatment strategies. We showed PCI had comparable outcomes to CABG in a cohort that had less favourable baselines characteristics such as heart failure and emergent presentation. There has been no contemporary studies of medical management for left mainstem disease. The medically managed patients had poor outcomes with high rates of myocardial infarction and death, which are remarkably similar to historical studies.

How might this impact on clinical practice?

- Our study supports the use of left mainstem PCI in selected patients. The study also shows that more consideration is needed before precluding patients from left mainstem revascularisation, considering the poor outcomes that were found in our study.

for surgical management, however with improvements in LMS percutaneous coronary intervention (PCI) with drug-eluting stents, this status quo has been challenged. ${ }^{2}$ Substudy findings of the large Synergy between PCI with Taxus and Cardiac Surgery (SYNTAX) trial have shown that drug-eluting PCI had comparable findings of death, myocardial infarction (MI) and composite of death MI and stroke, with PCI having higher rates of target vessel revascularisation (TVR) and coronary artery bypass graft (CABG) 
having higher rates of stroke. At higher lesion complexity and burden of coronary disease as judged by the SYNTAX score (>32), TVR was higher in the PCI arm and therefore those patients were reserved for surgery where possible. ${ }^{34}$

2014 saw guidance from both European Society of Cardiology (ESC) and American College of Cardiology/ American Heart Association (ACC/AHA) for LMS revascularisation. ESC gave PCI a class 1 indication for LMS stenosis with SYNTAX <22, IIA 23-32 and 3 for $>32$, with ACC/AHA giving PCI 2a for SYNTAX $<22$, 2b for 23-32 and also class 3 SYNTAX $>32$, with CABG maintaining class 1 for all complexities of coronary disease. ${ }^{45}$ LMS PCI has therefore been reserved for patients who are unfit for surgical revascularisation in clinical practice.

Since the 2014 guidelines two major randomised controlled trials published different outcomes in comparing CABG with PCI for LMS disease. EXCEL (Everolimus-eluting stents or bypass surgery for left main coronary artery disease) claimed non-inferiority of PCI to CABG with a primary endpoint of death, stroke and MI at 3 years ( 15.4 vs $14.7 \% \mathrm{p}=0.02$ for non-inferiority). ${ }^{6}$ NOBLE (Nordic-Baltic-British Left Main Revascularization Study) however concluded bleaker outcomes for PCI stating that CABG was superior to PCI for treatment of LMS disease. This was based on higher rate of major adverse cardiovascular event (MACE) at 5 years (28\% for PCI and $18 \%$ for CABG at 5 years $\mathrm{p}=0.0044) .{ }^{7}$ Important differences in primary endpoint of MACE should however be noted with NOBLE excluding procedural MI and including any revascularisation (therefore favouring $\mathrm{CABG}) .{ }^{8}$ We aimed to compare and contrast our patients 5 -year outcomes with significant LMS disease against the findings of these trials.

There have been no contemporary studies on medical management of LMS disease despite advances in medical

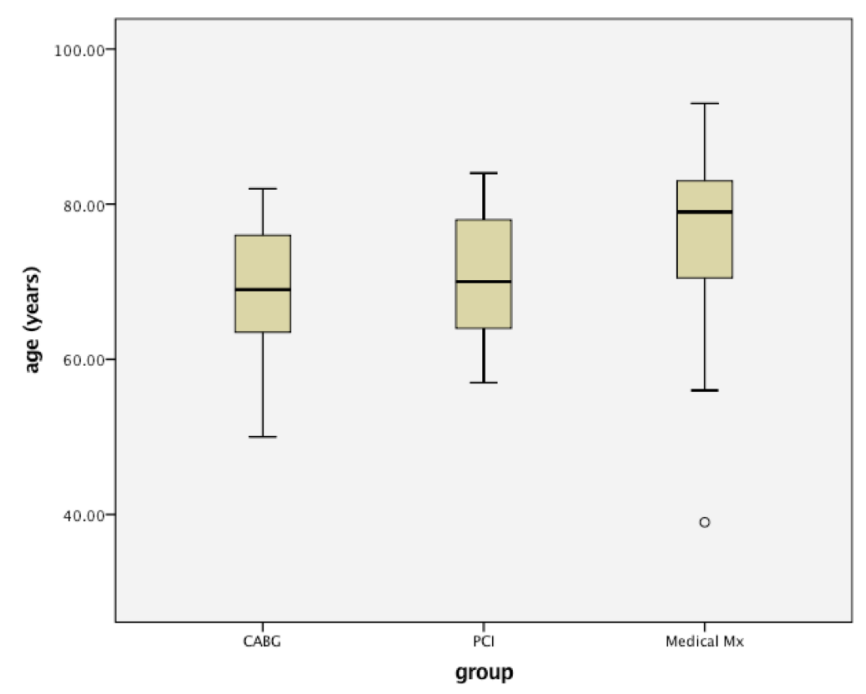

Figure 1 Boxplots to illustrate the differences in age groups between coronary artery bypass graft (CABG), percutaneous coronary intervention $(\mathrm{PCl})$, medical management (Medical $\mathrm{Mx})$. therapy such as more potent antiplatelets and widespread use of statins; however, classically figure 1 for this treatment modality is dire with the $57 \%-58 \%$ mortality at 5 years. $^{9} 10$

\section{METHODS}

We studied patients presenting with significant LMS disease to our hospitals in East Kent, UK. We retrospectively analysed coronary angiogram reports from 1 January 2012 to 31 December 2012 to identify patients with reported significant LMS stenosis on the initial angiogram, defined as angiographic stenosis $>50 \%$. We analysed the following 5 years to include data from surgical discharge summaries, catheter lab reports, echo reports and clinic letters to identify outcomes of these patients. Patients were grouped using intention-to-treat and statistical tests included student's t-test, $\chi^{2}$, Kruskal Wallis, Mann-Whitney $U$ and one-way analysis of variance (ANOVA) as necessary. There was no patient and public involvement in our study.

\section{RESULTS}

\section{Total cohort}

One hundred and nineteen patients were identified with angiographically significant LMS disease. Sixty-two per cent (74) received CABG, $12 \%$ (14) received PCI to LMS and 26\%(31) were medically managed as their initial treatment strategies. Eighty six per cent (102) were male, $14 \%$ (17) were female (table 1 ). Mean age was $70 \pm 9$ years. Follow-up time was 5 years from the initial angiogram.

\section{Baseline characteristics \\ Patients receiving CABG}

Seventy-four patients received CABG. Age was $69 \pm 8$ (SD) years, 92\% (68) were male. Mode of admission was stratified into emergency (ST-segment elevation myocardial infarction (STEMI), post arrest, malignant arrhythmia), acute (unstable angina, non-ST segment elevation myocardial infarction and elective indications (stable angina, investigation of heart failure, arrhythmia, preoperative assessment for valve intervention). Fifty-one per cent (38) received angiography electively, $43 \%$ (32) acutely and 5\% (4) emergently. Ostial/Mid shaft lesion were present in $45 \%$ (33) and distal lesions were in $55 \%$ (41). Number of non-LMS vessels with significant stenosis was $1.8 \pm 1.1$ with SYNTAX score of $24 \pm 9$. Twelve per cent (9) had diabetes mellitus. Sixteen per cent (12) had chronic kidney disease (CKD) (defined as estimated glomerular filtration rate $<90 \mathrm{~mL} / \mathrm{min}$ ), $35 \%$ (27) had hypertension, $14 \%$ (10) had a history of smoking and $5 \%$ (4) had a documented family history of ischaemic heart disease. Four per cent (3) had respiratory disease. Mean ejection fraction determined by echo was $52 \pm 13 \%$.

Of the 74 patients that received CABG, $7 \%$ (5) patients received valve intervention as well ( 3 patients received tissue aortic valve replacement and 2 patients received mitral valve repair). 
Table 1 Table to illustrate the baseline characteristics between the four groups

\begin{tabular}{|c|c|c|c|c|c|c|}
\hline & CABG & $\mathrm{PCl}$ & P value* & $\begin{array}{l}\text { Revascularised } \\
\text { (PCI/CABG) }\end{array}$ & $\begin{array}{l}\text { Medical } \\
\text { management }\end{array}$ & $\mathbf{P}$ value \\
\hline Total numbers & (74) & (14) & & $(88)$ & (31) & \\
\hline Male & $92 \%(68)$ & $71 \%(10)$ & 0.049 & $89 \%(78)$ & $77 \%(23)$ & 0.13 \\
\hline \multicolumn{7}{|l|}{ Mode of admission } \\
\hline Emergent & $5 \%(4)$ & $29 \%(4)$ & 0.08 & $9 \%(8)$ & $23 \%(7)$ & 0.11 \\
\hline \multicolumn{7}{|l|}{ Type of Iesion } \\
\hline Ostial/mid shaft & $45 \%(33)$ & $21 \%(3)$ & 0.09 & $41 \%(36)$ & $42 \%(13)$ & 0.54 \\
\hline Distal/bifurcation & $55 \%(41)$ & $79 \%(11)$ & & $59 \%(55)$ & $58 \%(18)$ & \\
\hline Diabetes mellitus & $12 \%(9)$ & $14 \%(2)$ & 0.83 & $13 \%(11)$ & $16 \%(5)$ & 0.76 \\
\hline CKD & $16 \%(12)$ & $14 \%(2)$ & 0.86 & $16 \%(14)$ & $10 \%(3)$ & 0.39 \\
\hline \multicolumn{7}{|l|}{ Risk factor profile } \\
\hline HTN & $36 \%(27)$ & $29 \%(4)$ & 0.52 & $35 \%(31)$ & $42 \%(13)$ & 0.52 \\
\hline Smoking & $14 \%(10)$ & $0(0 \%)$ & 0.14 & $11 \%(10)$ & $6 \%(2)$ & 0.23 \\
\hline Family history & $5 \%(4)$ & $0(0 \%)$ & 0.37 & $5 \%(4)$ & $3 \%(1)$ & 0.75 \\
\hline Lung disease & $4 \%(3)$ & $14 \%(2)$ & 0.13 & $6 \%(5)$ & $6 \%(2)$ & 0.88 \\
\hline Ejection fraction & $52 \% \pm 13$ & $42 \% \pm 10$ & 0.01 & $50 \% \pm 13$ & $48 \% \pm 15$ & 0.4 \\
\hline
\end{tabular}

${ }^{*} \mathrm{P}$ value for significance between coronary artery bypass graft (CABG) and percutaneous coronary intervention (PCI).

†P value for significance between medical management and revascularisation, that is, $\mathrm{PCl}$ or CABG.

MACE, major adverse cardiovascular event-composite between MI, TVR, stroke and all-cause mortality; MI, myocardial infarction; SYNTAX,

Synergy between PCI with Taxus and Cardiac Surgery; TVR, target vessel revascularisation.

Seventy per cent $(95 \%)$ of 74 patients underwent left internal mammary artery grafting, $3(4 \%)$ underwent right internal mammary grafting, $72(97 \%)$ underwent venous grafting. The number of grafts per patient was 1 in $2(3 \%)$ patients, 2 in $17(23 \%)$ patients, 3 in $38(51 \%)$ patients and 4 in $17(23 \%)$ patients.

\section{Patients receiving $\mathrm{PCl}$}

Fourteen patients received LMS PCI. Mean age was $71 \pm 8$ years. Seventy-one per cent (10) were male. Mode of admission as defined as above were $43 \%$ (6) for elective, $29 \%$ (4) acute and 29\% (4) were emergent presentations. Seventy-nine per cent(11) were distal/bifurcation lesions with $21 \%$ (3) being ostial/mid-shaft. There were $1.7 \pm 1.0$ non-LMS vessels with significant stenosis and mean SYNTAX score was $25 \pm 8$. Fourteen per cent (2) had diabetes mellitus, $14 \%$ (2) had CKD, 29\% (4) had hypertension, no one had a documented smoking or family history and $14 \%$ (2) had a history of respiratory disease. Mean ejection fraction determined by echocardiography was $42 \pm 10 \%$.

Among the 14 PCI treated patients, $6(43 \%)$ had isolated treatment for left main stem disease, $6(43 \%)$ of 1 additional lesion treated, and $2(14 \%)$ had 2 additional lesions treated. Treatment for left main stem disease involved the bifurcation in $11(79 \%)$. A secondgeneration drug-eluting stent was implanted in the left main stem in $13(93 \%)$ and $1(7 \%)$ had a bare metal stent. Intravascular ultrasound was used to guide implantation in $2(14 \%)$ and fractional flow reserve was used in $5(36 \%)$ of cases.

\section{Medically managed patients}

Mean age for the medically managed group of patients was $75 \pm 11 \%$ and $77 \%$ (23) were male. Forty-five per cent (14) of patients had their initial angiogram electively, 32\% (10) acutely and 23\% (7) as an emergency. Forty-two per cent (13) had ostial or mid-shaft lesions and $58 \%$ (18) had distal/bifurcation lesions. There were mean $1.99 \pm 1.0$ non-LMS vessels with significant stenosis and mean SYNTAX score was $25 \pm 9$. 16\% (5) had diabetes mellitus, $10 \%$ (3) had CKD, $42 \%$ (13) had hypertension, $6 \%$ (2) had a history of smoking, $3 \%$ (1) had a family history of ischaemic heart disease, $6 \%$ (2) had respiratory disease and mean ejection fraction was $48 \% \pm 15$. 
Table 2 Table to illustrate the difference in outcomes between the four groups

\begin{tabular}{lllllll}
\hline & CABG & PCI & P value* & $\begin{array}{l}\text { Revascularised } \\
\text { (CABG/PCI) }\end{array}$ & Medical management & P value $^{\star *}$ \\
\hline MI & $3 \%(2)$ & $0 \%(0)$ & 0.53 & $2 \%(2)$ & $19 \%(6)$ & 0.01 \\
TVR & $1 \%(1)$ & $0 \%(0)$ & 0.66 & $1 \%(1)$ & $0 \%(0)$ & 0.55 \\
Stroke & $1 \%(1)$ & $14 \%(2)$ & 0.01 & $3 \%(3)$ & $6 \%(2)$ & 0.47 \\
All cause mortality & $19 \%(14)$ & $21 \%(3)$ & 0.83 & $19 \%(17)$ & $52 \%(16)$ & 0.01 \\
MACE & $23 \%(17)$ & $36 \%(5)$ & 0.12 & $25 \%(22)$ & $74 \%(23)$ & 0.000002 \\
\hline
\end{tabular}

CABG, coronary artery bypass graft; MACE, major adverse cardiovascular event; composite of stroke, MI, TVR and all-cause mortality; MI, myocardial infarction; PCl, percutaneous coronary intervention; TVR, target vessel revascularisation.

\section{PCI versus CABG group comparison and outcomes}

There was no significant difference in age $p=0.76$. There was a significantly higher proportion of men in the CABG group $(92 \%$ (68) vs $71 \%(10), \mathrm{p}=0.049)$. There was a trend towards significantly higher proportion of patients receiving PCI emergently as opposed to CABG (29\% (4) vs $5 \%(4), \mathrm{p}=0.08)$. There was no significant difference in acute $(p=0.39)$ or elective $(p=0.57)$ presentations. There was a trend towards higher distal/bifurcation lesions in the PCI group 79\% (11) versus 55\% (41) $\mathrm{p}=0.09$. There was no significant difference in SYNTAX score $(\mathrm{p}=0.68)$ or number of non-LMS vessels with significant stenosis $(\mathrm{p}=0.63)$. There was no significant difference in proportion of patients with diabetes mellitus $(\mathrm{p}=0.83)$, CKD $(\mathrm{p}=0.86)$, hypertension $(\mathrm{p}=0.52)$, history of smoking $(\mathrm{p}=0.14)$, family history $(\mathrm{p}=0.37)$ and respiratory disease $(p=0.13)$. Ejection fraction was significantly lower in the PCI group $(42 \% \pm 10$ vs $52 \% \pm 13, \mathrm{p}=0.01)$.

There was no significant difference in MI (defined using the Fourth Universal Definition of MI including periprocedural $^{11}$ ) between CABG or PCI (3\% (2) vs $0 \%, \mathrm{p}=0.53)$, TVR $(1 \%(1)$ vs $0 \%, \mathrm{p}=0.66)$ and all-cause mortality ( $19 \%$ (14) vs $21 \%$ (3), $\mathrm{p}=0.83$; table 2$)$. There was a significantly higher rate of stroke in the PCI group ( $14 \%$ (2) vs $1 \%$ (1), p=0.01). MACE defined as composite of MI, TVR, stroke and all-cause mortality was not significantly different between the two groups although numerically higher in the PCI group (36\% (5) vs $23 \%$ (17), $\mathrm{p}=0.12$ ).

\section{Revascularised (PCI/CABG) versus medically managed group comparison and outcomes}

Patients that were medically managed were significantly older than those that were revascularized (either PCI or CABG $n=88$; 75 years \pm 11 vs 69 years $\pm 9, p=0.01)$. There was no significant difference in elective $(p=0.4)$, acute $(\mathrm{p}=0.43)$ or emergent $(\mathrm{p}=0.11)$ presentations. There was no significant difference in ostial versus bifurcation lesions $(p=0.54)$. There was no significant difference in proportion of patients with diabetes mellitus $(\mathrm{p}=0.76)$, CKD ( $\mathrm{p}=0.39)$, hypertension $(\mathrm{p}=0.52)$, smoking history $(p=0.23)$, family history of ischaemic heart disease $(p=0.75)$, respiratory disease $(p=0.88)$ or ejection fraction $(\mathrm{p}=0.4)$.
There was a higher rate of MI in the medically managed group compared with patients that were revascularized with either PCI or CABG (19\% (6) vs $2 \%$ (2) $\mathrm{p}=0.01)$. There was no significant difference in TVR $(1 \%$ (1) vs $0 \%(0), \mathrm{p}=0.55)$ and stroke (6\% (2) vs $3 \%(3), \mathrm{p}=0.47)$. There was a higher all-cause mortality in the medically managed group $(52 \%$ (16) vs $19 \%(17), \mathrm{p}=0.01$ ) and significantly higher MACE rate defined as above $(74 \%$ (23) vs $25 \%$ (22), $\mathrm{p}=0.000002$ ).

\section{Subgroup analysis based on SYNTAX score}

In the whole cohort (all-comers with left main stem disease), $25(21 \%)$ of patients had a SYNTAX score $>32$ and $94(79 \%)$ had SYNTAX <32. Patients with SYNTAX $>32$ had a higher MACE $(60 \%$ (15) vs $33 \%$ (31), $\mathrm{p}=0.013)$, which was due to a higher mortality (52\% (13) vs $21 \%(20), p=0.003)$. There was no significant difference in stroke $(\mathrm{p}=0.24)$, MI $(\mathrm{p}=0.47)$ or TVR $(\mathrm{p}=0.79)$ based on SYNTAX score.

Of the patients receiving CABG, $18 \%$ (13) had a SYNTAX score $>32$. Of the patients receiving PCI, $21 \%$ (3) had SYNTAX score $>32$. In those treated with CABG, there was no significant difference in MACE between patients with SYNTAX >32 (13) versus those with SYNTAX $<32$ (61) (38\% (5) vs 20\% (12), p=0.14). In patients treated with PCI, there was a trend towards a higher rate of MACE in those with SYNTAX >32 versus those with SYNTAX <32 $(27 \%(3 / 11)$ vs $100 \%(3 / 3), p=0.055)$.

\section{DISCUSSION}

The main findings of our study were that PCI had a numerically higher rate of MACE than CABG although this did not reach statistical significance. This reflects the findings of NOBLE as opposed to EXCEL with a higher MACE (PCI 28\% vs CABG 18\% in NOBLE over 5 years). Mortality was not significantly different between the two cohorts and unlike patients receiving CABG, no patient in the PCI arm had further MI or TVR. This is taking into account a higher rate of heart failure, emergent presentation and distal/bifurcation disease in the PCI group. Patients that were medically managed had significant higher rate of MI and MACE, and all-cause mortality was also very high (52\%). A modest sample size particularly 
in the PCI group means that we cannot advocate for one method of revascularisation of the other using this data; however, we can gain insightful observations on the influence of clinical, anatomical and procedural characteristics on outcomes.

There was no significant difference in age between PCI and CABG. Interestingly, there was a higher proportion of men who offered CABG than PCI. This may give some influence on outcomes as it has been demonstrated in a previous study that female gender favours CABG in terms of 4-year mortality in EXCEL. ${ }^{12}$ Age in EXCEL and NOBLE was approximately 66 years for both treatment modalities, however enrolment depended on clinical equipoise between both strategies and therefore would have resulted in the exclusion of a large proportion of those over $75 .{ }^{67}$

There was a significantly higher incidence of left ventricular systolic dysfunction in the PCI-treated group. The influence of heart failure on outcomes following PCI and CABG in patients with significant left main stem disease remains unclear with only $7.1 \%$ and $6.7 \%$ in PCI and CABG in EXCEL with heart failure and even fewer in NOBLE. There was a higher numerical event rate in EXCEL in those with ejection fraction of less than $50 \%$, however not significantly different due to low patient numbers. The presence of heart failure may preclude surgery due to surgical risk and therefore tip the balance towards PCI. However, a recent metanalysis has shown survival benefit with both revascularisation strategies with CABG having favourable outcomes compared with PCI (HR 0.82, $\mathrm{p}<0.001) .{ }^{13}$ This is further emphasised in the STICH (Surgical Treatment for Ischemic Heart Failure) trial which showed a reduction in cardiovascular death and hospitalisation from cardiac causes in CABG as compared with medical therapy alone in patients with coronary disease and heart failure. ${ }^{14}$

Patients receiving LMS PCI had similar SYNTAX scores to those receiving CABG where guidelines reserve PCI for those with lower SYNTAX scores. Three patients receiving LMS PCI had SYNTAX score $>32$ where PCI is a class IIIb indication; however, two of these patients received PCI in the context of STEMI and one was turned down for surgery due to previous stroke. Limitations of SYNTAX were uncovered in the EXCEL trial where $17 \%$ of PCI patients and 14\% of CABG patients had SS scores $>32$ despite it being a low SYNTAX trial. ${ }^{5}$ Despite these limitations, SYNTAX > 32 was strongly predictive of MACE in the PCI arm and MI and MACE in the whole cohort independent of revascularisation method. Our data therefore support the stratification of high SYNTAX scores to the CABG as a preferred method of revascularisation. There was a trend towards more distal/ bifurcation left main stem lesions in the PCI group which can have significant influences on revascularisation rates as it has been found to be associated with higher ischaemia driven revascularisation in PCI when compared with CABG from a substudy of the EXCEL trial (13 vs $7.2 \%$, $\mathrm{p}=0.0001) .^{15}$
There was a trend towards PCI being performed more on those with STEMI (ie, on an emergent basis). In the Asia-pacific Left main ST-Elevation Registry study, STEMI in the setting of LMS disease resulted in a high in-hospital mortality of $47.8 \%$ compared with the $1 \% 30$ days mortality found in EXCEL. ${ }^{16}$ Patients with STEMI were excluded in NOBLE and had only 1.6\%-1.7\% of EXCEL patients were recruited with STEMI in PCI and CABG, respectively. ${ }^{6}$ Even in SYNTAX, acute MI was excluded. Despite a higher rate of STEMI in our PCI cohort, outcomes remained comparable between CABG and PCI.

Interestingly, in our cohorts a higher proportion of patients had a stroke in the PCI treated group compared with, although in very low numbers. This was paralleled in the NOBLE trial with a numerically higher rate of stroke in PCI versus CABG (4.9\% vs 2\%); however, this did not quite reach significance $(p=0.08) .^{7}$ The result contrasted the SYNTAX trial which found a higher rate of stroke in the CABG group at long term follow-up. The NOBLE authors did propose this to be a chance finding due to low numbers in both groups similar to our cohort. Furthermore, this finding was not reflected in the EXCEL trial which showed no significant difference in stroke at 3 years $(2.9 \% \mathrm{CABG}$ vs $2.3 \%$ PCI, $\mathrm{p}=0.37){ }^{6}$

Medically, management of LMS disease in our cohort carried very poor outcomes compared with those with revascularisation with higher rates of further MI, all-cause mortality (being particularly high 52\%) and MACE. It is striking how similar our results compare to studies from many decades ago given improvements in medical management that have emerged, namely higher intensity antiplatelets and statins. Our medically managed patients had a high incidence (19\%) of MI in the 5 years of follow-up. Historic studies showed a slightly higher rate of MI at 28\%-30.7\% ${ }^{10}$ Reduction in MI in our medically managed patients may hint at improved contemporary medical optimisation. However, the rate of MI in EXCEL and NOBLE was 3\%-7\%. We cannot directly compare our medically managed cohort to the younger and less comorbid participants of large randomised trials; however, our observed high rate of further MI and mortality needs to be considered before precluding these patients from revascularisation.

The main distinguishing feature of the medically managed were that they were on average 5 years older than those that were revascularised. The risk factor profile and anatomical complexity were similar. A substudy of the EXCEL cohort reported 3-year MACE (in patients with both PCI or CABG) of $20.4 \%$ in those aged over 75 years compared with $14 \%<75$ years $\mathrm{p}=0.008^{18}$ (composite of death, stroke or MI). In a study of 304 octegenarians with LMS disease, MACE defined as death stroke or MI was $32.6 \%$ for PCI versus CABG $30.2 \% \mathrm{p}=0.69$ at 3 years. ${ }^{19}$ We consider that age should not be a pivotal feature in risk assessment of those with left main disease considering the far higher MACE rate that has been found in our medically managed group. We acknowledge however that other factors of frailty that we have not measured 
such as mobility, cognition or bleeding risk may have played a role in clinical decision-making.

\section{Limitations}

We acknowledge the overall small numbers for recorded events and components of MACE. Data collection also dependant on the detailed documentation in discharge summaries and clinic letters and therefore there is potential to miss certain baseline characteristics in particular.

\section{CONCLUSION}

The real-world findings of our naturalistic observational study support the use of LMS PCI in selected patients with comparable cardiovascular outcomes to those undergoing $\mathrm{CABG}$, despite presenting emergently and with a higher rate of heart failure. The cohort of patients with medically managed LMS disease suffered with high rates MACE driven by MI and all-cause mortality reflecting the findings of historical studies performed several decades ago. More careful consideration is needed in precluding patients with significant LMS disease from revascularisation considering the prognosis suggested by our study.

Contributors GJ is the guarantor for this study, leading on planning, conducting and reporting of the work. HE has significantly contributed to data collection and analysis for the study.

Funding The authors have not declared a specific grant for this research from any funding agency in the public, commercial or not-for-profit sectors.

Competing interests None declared.

Patient consent for publication Not required.

Ethics approval The study was given approval by the local research and audit department and complies with the Declaration of Helsinki.

Provenance and peer review Not commissioned; externally peer reviewed.

Data availability statement № data are available.

Open access This is an open access article distributed in accordance with the Creative Commons Attribution Non Commercial (CC BY-NC 4.0) license, which permits others to distribute, remix, adapt, build upon this work non-commercially, and license their derivative works on different terms, provided the original work is properly cited, appropriate credit is given, any changes made indicated, and the use is non-commercial. See: http://creativecommons.org/licenses/by-nc/4.0/.

ORCID iD

George Joy http://orcid.org/0000-0003-1467-5490

\section{REFERENCES}

1 Dash D. Stenting of left main coronary artery stenosis: a to Z. Heart Asia 2013;5:18-27.

2 De Maria GL, Patel N, Banning AP. Obstructive left main stem coronary disease: is it time to recommend coronary stenting? Heart 2018;104:614-20.
3 Thuijs DJFM, Kappetein AP, Serruys PW, et al. Percutaneous coronary intervention versus coronary artery bypass grafting in patients with three-vessel or left main coronary artery disease: 10-year follow-up of the multicentre randomised controlled SYNTAX trial. The Lancet 2019;394:1325-34.

4 Authors/Task Force members, Windecker S, Kolh P, et al. 2014 ESC/EACTS Guidelines on myocardial revascularization: The Task Force on Myocardial Revascularization of the European Society of Cardiology (ESC) and the European Association for Cardio-Thoracic Surgery (EACTS)Developed with the special contribution of the European Association of Percutaneous Cardiovascular Interventions (EAPCI). Eur Heart J 2014;35:2541-619.

5 Fihn SD, Blankenship JC, Alexander KP, et al. 2014 ACC/AHA/AATS/ PCNA/SCAI/STS focused update of the Guideline for the diagnosis and management of patients with stable ischemic heart disease. Circulation 2014;130:1749-67.

6 Stone GW, Sabik JF, Serruys PW, et al. Everolimus-Eluting stents or bypass surgery for left main coronary artery disease. N Engl J Med 2016;375:2223-35.

7 Mäkikallio T, Holm NR, Lindsay M, et al. Percutaneous coronary angioplasty versus coronary artery bypass grafting in treatment of unprotected left main stenosis (noble): a prospective, randomised, open-label, non-inferiority trial. The Lancet 2016;388:2743-52.

8 Gershlick AH, Banning A. Contemporary considerations in left main stem treatment. Eurolntervention 2017:13:1144-7.

9 Bruschke AVG, Proudfit WL, Sones FM. Progress study of 590 consecutive nonsurgical cases of coronary disease followed 5-9 years. Circulation 1973;47:1154-63.

10 Taylor HA, Deumite NJ, Chaitman BR, et al. Asymptomatic left main coronary artery disease in the coronary artery surgery study (CASS) registry. Circulation 1989;79:1171-9.

11 Thygesen K, Alpert JS, Jaffe AS, et al. Fourth universal definition of myocardial infarction (2018). Eur Heart J 2019;40:237-69.

12 Campos CM, van Klaveren D, Farooq V, et al. Long-Term forecasting and comparison of mortality in the evaluation of the Xience everolimus Eluting stent vs. coronary artery bypass surgery for effectiveness of left main revascularization (EXCEL) trial: prospective validation of the SYNTAX score II. Eur Heart $J$ 2015;36:1231-41.

13 Wolff G, Dimitroulis D, Andreotti F, et al. Survival benefits of invasive versus conservative strategies in heart failure in patients with reduced ejection fraction and coronary artery disease: a metaanalysis. Circ Heart Fail 2017;10:e003255.

14 Velazquez EJ, Lee KL, Deja MA, et al. Coronary-Artery bypass surgery in patients with left ventricular dysfunction. $N$ Engl J Med 2011;364:1607-16.

15 Gershlick AH, Kandzari DE, Banning A, et al. Outcomes After Left Main Percutaneous Coronary Intervention Versus Coronary Artery Bypass Grafting According to Lesion Site: Results From the EXCEL Trial. JACC Cardiovasc Interv 2018;11:1224-33.

16 Yap J, Singh GD, Kim J-S, et al. Outcomes of primary percutaneous coronary intervention in acute myocardial infarction due to unprotected left main thrombosis: the Asia-Pacific left main STelevation registry (aster). J Interv Cardiol 2018;31:129-35.

17 Yusuf S, Zucker D, Peduzzi P, et al. Effect of coronary artery bypass graft surgery on survival: overview of 10 -year results from randomised trials by the coronary artery bypass graft surgery Trialists collaboration. Lancet 1994;344:563-70.

18 Schampaert E, Serruys P, Kappetein AP, et al. TCT-78 outcomes of left main revascularization in the elderly and younger patients: the EXCEL trial. J Am Coll Cardiol 2017;70:B34.

19 Conrotto F, Scacciatella P, D'Ascenzo F, et al. Long-Term outcomes of percutaneous coronary interventions or coronary artery bypass grafting for left main coronary artery disease in octogenarians (from a drug-eluting stent for left main artery registry substudy). $A m \mathrm{~J}$ Cardiol 2014;113:2007-12. 